\title{
Negative Spiritual Experiences and Psychological Flourishing
}

\author{
Gabriel S Dy-Liacco ${ }^{1 *}$ and Mary Beth Werdel ${ }^{2}$ \\ ${ }^{1}$ Divine Mercy University, USA \\ ${ }^{2}$ Fordham University, USA
}

*Corresponding author: Gabriel S Dy-Liacco, Associate Professor, Divine Mercy

University, USA, Tel: +63.917.828.4987; Email: gsd.phd@gmail.com

\section{Research Article}

Volume 3 Issue 1

Received Date: June 08, 2019

Published Date: June 28, 2019

DOI: $10.23880 / \mathrm{mhrij}-16000127$

\section{Abstract}

Psychological studies on the spiritual experience of religiously committed individuals have typically focused on positive spiritual experiences and their impact on psychological flourishing. This study examined two structural equation models of the potential short-term impact of negative spiritual experiences on the psychological flourishing of religiously committed individuals. Modeling results were: a) negative and positive spiritual experiences together emerged as the underlying cause of psychological flourishing, rather than the reverse, and, b) when taken together with positive spiritual experiences, negative spiritual experiences had a significant immediate negative association with psychological flourishing whereas positive spiritual experiences did not have a statistically significant association. These modeling results were discussed in light of the "bad stronger than good" theory of the greater immediate impact of negative events on psychological outcomes. Negative spiritual experiences appear to have similar salience to non-spiritual negative events.

Keywords: Spirituality; Spiritual Struggles; Negative Spiritual Experience; Psychological Flourishing; Subjective Well Being; Structural Equation Model

\section{Introduction}

How might the perceptions of God as abandoning or punishing and the feeling of being disconnected from one's faith community (i.e., spiritual struggles) affect the mental life of a religiously committed individual? This is a salient question in the psychology of religion as the human experience of religion and spirituality has been linked to both excitatory and inhibitory systems of the brain and their corresponding cognitive-affective states $[1,2]$. Much of the research in the psychology of religion has focused on positive religious and spiritual experience as these relate to excitatory systems and positive cognitive-affective states. For example, the edited volumes of Koenig, Kind, and Carson [3] and Paloutzian and Park [4] contain numerous examples of studies that demonstrate the capacities of religious and spiritual variables to correlate with or uniquely predict higher levels of variables associated with human flourishing. This line of research on positive spiritual variables and improved health and psychosocial outcomes has laid important groundwork for the scientific consideration of religious and spiritual variables as protective factors in mental health and cross-cultural markers of quality of life $[5,6]$.

However, a focus on positive experiences captures only half of the picture of the structure and function of spiritual experience in the human psychological system. Fewer studies have investigated the relationships 


\section{Mental Health \& Human Resilience International Journal}

between negative spiritual experiences and psychological flourishing or languishing, thus leaving room for modeltesting and theory-building in this area [7]. This is especially relevant in our times as a comprehensive review of empirical studies on the impact of negative versus positive events has shown that bad events have a more intense and longer lasting impact than do good ones across a wide range of variables: reactions to events, relationships, emotional experience, learning, child development, social support, information processing, memory, stereotyping, forming impressions, self-esteem, and health [8]. Baumeister, et al. [8] found that negative events impacted both negative and positive outcomes in each of these areas, whereas positive events impacted only positive outcomes.
The present study will assess the immediate potential impact of negative spiritual experiences vis-à-vis positive spiritual experiences on psychological states. This will be accomplished through an evaluation of two structural equation models. Model 1 (Figure 1) posits short-term potential causal effects of negative versus positive spirituality on psychological flourishing. Model 2 (Figure 2) posits psychological flourishing as the cause of spirituality and will be evaluated in order to determine the direction of effects. The hypotheses of this study are: a) spirituality will be the underlying cause of psychological flourishing (Figure 1), rather than the reverse (Figure 2), and, b) in the short term, negative spiritual experiences will have significantly greater unique effects than positive spiritual experiences on psychological flourishing (Figure 1).

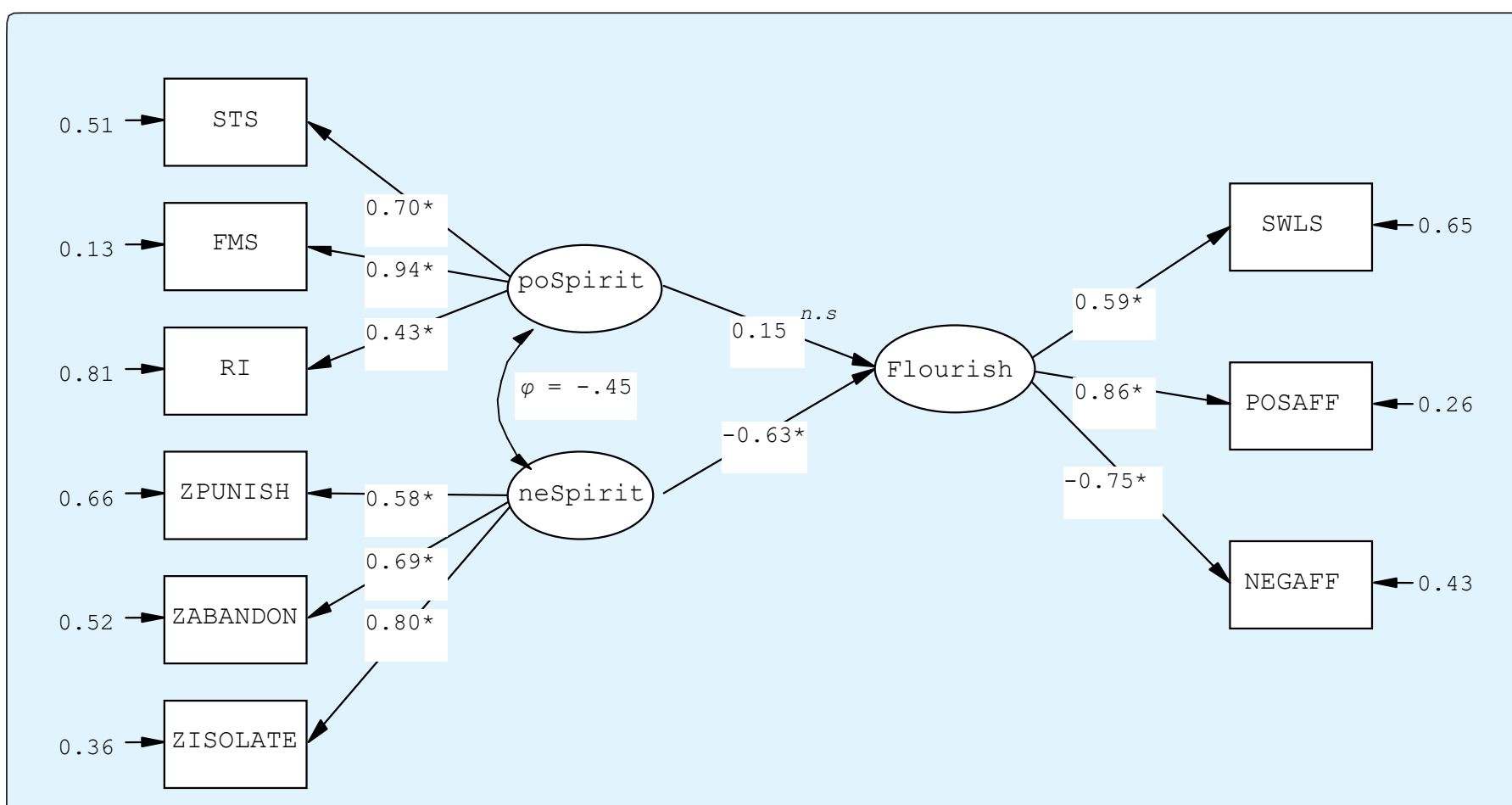

Figure 1: Structural Model of Positive and Negative Spirituality Predicting Psychological Flourishing.

Note: Model $1 \chi^{2} s-B(24)=33.46, p=.10$. poSpirit: positive spirituality. neSpirit: negative spirituality. Flourish: psychological flourishing. STS: Spiritual Transcendence Scale. FMS: Faith Maturity Scale. RI: 4-item religious involvement scale. ZPUNISH: item on feeling punished by God. ZABANDON: item on feeling abandoned by God. ZISOLATE: item on feeling isolated from one's faith community. SWLS: Satisfaction with Life Scale. POSAFF: positive affect score from the Positive and Negative Affect Schedule. NEGAFF: negative affect score from the Positive and Negative Affect Schedule.

${ }^{*} p<.05 ;$ n.s.: non-significant. 


\section{Mental Health \& Human Resilience International Journal}

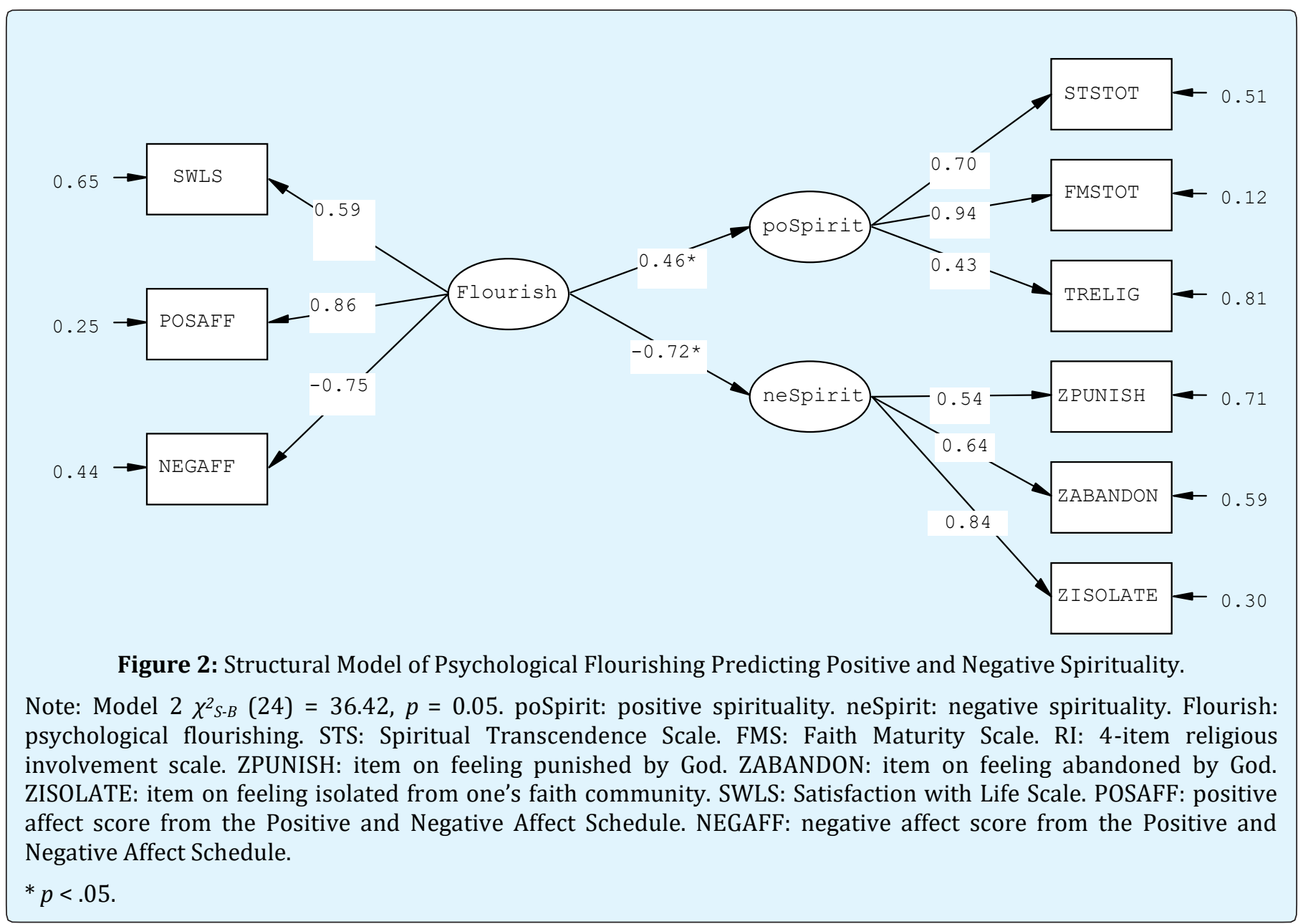

\section{Method}

\section{Participants}

Participants were a cross-sectional sample of 177 religiously committed adult volunteers recruited by counselling graduate students at two private U.S. east coast universities who were taking an introductory research course $(91.8 \%$ Christian; 68\% Female; Mean Age $=41, S D=15 ; 52 \%$ Caucasian, 32\% African-American, $1 \%$ Asian, 2\% Hispanic and 4\% Other, and 9\% did not endorse an ethnicity/race category). Students received course credit for participating in data collection.

\section{Measures}

\section{Spirituality Indicators}

Assessment of Spiritual and Religious Sentiments (ASPIRES): Piedmont [9] designed the ASPIRES to capture spiritual transcendence (ST), religious involvement (RI), religious crisis (RC), and demographic data such as age, gender, and religious affiliation. Spiritual transcendence is defined as the individual's tendency to create a broad sense of personal meaning in light of the awareness of one's finitude. Religious involvement (RI) is defined as frequencies of prayer, reading primary and secondary religious literature, and attending religious services. Religious crisis (RC) is defined as a perception of alienation from God marked by a sense of abandonment, being punished, and isolation from one's faith community.

In this study, the ASPIRES provided two of the 3 indicators of positive spirituality and all 3 indicators of negative spirituality (spiritual struggles). Positive spirituality indicators were: the 23-item Spiritual Transcendence Scale (STS) total scores (STSTOT) and the 4-item RI scores (TRELIG). The STS is thought to capture three facets of ST, namely, prayer fulfilment, universality, 


\section{Mental Health \& Human Resilience International Journal}

and connectedness. Prayer fulfillment is defined as a feeling of joy and contentment that results from personal encounters with a transcendent reality; universality is defined as a belief in the unitive nature of life; and, connectedness is defined as a belief that one is part of a larger human reality that cuts across generations and across groups. Negative spirituality indicators were zscores of single items capturing the sense of abandonment (ZABANDON) and punishment (ZPUNISH) by God, and a single item capturing the sense of isolation from one's faith community (ZISOLATE). Alpha reliabilities of scores for the STS, RI and the RC scales were $.86, .83$, and .72 , respectively.

Faith Maturity Scale (FMS) 11-item short form: Developed by Benson, Donahue, and Erikson [10], the FMS captures an individual's sense of closeness to God (vertical faith) and the degree to which this perceived relationship leads to acts of altruism and social justice (horizontal faith). The FMS provides scores for vertical, horizontal, and total faith maturity. The total FMS score (FMSTOT) was used in this study as the third indicator of positive spirituality. The total score is obtained by summing responses to all items of the 11-item short form normed by Piedmont and Nelson [11]. Reliability of FMS scores in this sample was .90 .

\section{Psychological Flourishing Indicators}

Positive and Negative Affect Schedule (PANAS): Developed by Watson, Clark and Tellegen [12], the PANAS is a 20-item measure that returns separate scores for positive affect (POSAFF) and negative affect (NEGAFF). Alpha reliability of scores in this sample were .86 and .80 , respectively. These were used as two of the 3 indicators for psychological flourishing.

Satisfaction with Life Scale (SWLS): Developed by Diener, Emmons, Larsen and Griffin [13], this 5-item scale was designed to measure global cognitive judgments of satisfaction with one's life. This was used as the third indicator of psychological flourishing and the reliability of scores in this sample was .88.

\section{Personality Measure}

International Personality Item Pool 50-item version (IPIP-NE0-50; http://ipip.ori.org) [14]: The domains of the five factor model of personality were measured for the incremental validity check using the 50 -item version of the IPIP-NEO [15]. The IPIP-NEO domain scores in this study had the following internal consistency reliability estimates of .83, .86, .76, .78, and 79 for neuroticism, extraversion, openness, agreeableness, and conscientiousness, respectively. The order of measures was randomized per participant in order to minimize any order effects.

\section{Model Specification and Data Analytic Technique}

Incremental validity check: Incremental validity analyses were performed using hierarchical multiple regression and $F$-tests prior to the analyses of the SEMs [16]. Each outcome indicator (satisfaction with life, negative affect, and positive affect) was regressed on the five domains of personality entered as a block on the first step of the regression model, and the scores of positive spirituality (spiritual transcendence, faith maturity, and religious involvement) and negative spirituality (abandoned by God, punished by God, and isolated from faith community) indicators were entered as a block on the second step of the regression model. These validity checks were performed in order to ascertain that the spiritual variables were able to explain the outcomes above and beyond what is already explained by the domains of the five-factor model of personality (Piedmont, 2006 [17], for the overall value of such analyses). If the spirituality variables demonstrate incremental validity, then the authors will proceed with the SEM analyses. If, however, there is no incremental validity, then this would mean that the SEM analyses of spirituality are not necessary to understand psychological flourishing because any individual differences in flourishing would be explained by personality traits alone.

Structural equation models: Two models were evaluated. In both models, constructs were indicated as follows. Positive spirituality (poSpirit) was indicated by the STS, FMS, and RI total scale scores. Negative spirituality (neSpirit) was indicated by single item zscores of feeling punished by God (ZPUNISH), abandoned by God (ZABANDON), and isolated from one's faith community (ZISOLATE). Z-scores of negative spirituality items were used to standardize their metrics. Psychological flourishing was indicated by the traditional subjective well-being measures of satisfaction with life (SWLS), positive affect (POSAFF) and negative affect (NEGAFF). Structural equation modeling analyses were conducted with LISREL 8.72 [18]. Covariance and asymptotic covariance matrices were prepared in PRELIS, and the models were estimated using the Robust ML extraction method for small sample multivariate nonnormal continuous data. The raw data file is available from the first author and an intercorrelation matrix with means and standard deviations are provided in Table 1. Model 1 (Figure 1) specified positive and negative 


\section{Mental Health \& Human Resilience International Journal}

spirituality as predictors of psychological flourishing. Model 2 (Figure 2) specified psychological flourishing as the predictor of positive and negative spirituality.

\begin{tabular}{|c|c|c|c|c|c|c|c|c|c|}
\hline Scale & $\mathbf{1}$ & $\mathbf{2}$ & $\mathbf{3}$ & $\mathbf{4}$ & $\mathbf{5}$ & $\mathbf{6}$ & $\mathbf{7}$ & $\mathbf{8}$ & $\mathbf{9}$ \\
\hline Spiritual Transcendence & - & & & & & & & & \\
\hline Faith Maturity & $.66^{* * *}$ & - & & & & & & & \\
\hline Religious Involvement & $.25^{* * *}$ & $.42^{* * *}$ & - & & & & & & \\
\hline Punished by God a & $-.21^{* *}$ & $-.22^{* *}$ & -0.01 & - & & & & & \\
\hline Abandoned by God a & $-.27^{* * *}$ & $-.31^{* * *}$ & $-.18^{*}$ & $.46^{* * *}$ & - & & & & \\
\hline solated from faith a community & $-.28^{* * *}$ & $-.33^{* * *}$ & $-.17^{*}$ & $.49^{* * *}$ & $.51^{* * *}$ & - & & & \\
\hline Satisfaction with Life & $.29^{* * *}$ & $.27^{* * *}$ & 0.06 & $-.18^{*}$ & $-.41^{* * *}$ & $-.32^{* * *}$ & - & & \\
\hline Positive Affect b & $.34^{* * *}$ & $.36^{* * *}$ & 0.11 & $-.22^{* *}$ & $-.42^{* * *}$ & $-.53^{* * *}$ & $.49^{* * *}$ & - & \\
\hline Negative Affect b & $-.28^{* * *}$ & $-.25^{* * *}$ & 0.003 & $.21^{* *}$ & $.39^{* * *}$ & $.41^{* * *}$ & $-.47^{* * *}$ & $-.66^{* * *}$ & - \\
\hline Mean & 92.85 & 57.14 & 41.06 & 0 & 0 & 0 & 24.71 & 15.05 & 5.25 \\
\hline SD & 10.86 & 11.25 & 10.14 & 1 & 1 & 1 & 6.56 & 3.68 & 3.47 \\
\hline
\end{tabular}

Note: List wise $\mathrm{N}=174$. a Single item $\mathrm{z}$-score. $\mathrm{b}$ Taken from the Positive and Negative Affect Schedule. ${ }^{*} \mathrm{p}<.05,{ }^{* *} \mathrm{p}<.01$, $* * * \mathrm{p}<.001$.

Table 1: Correlations, Means, and Standard Deviations of Spirituality and Well-Being Scale Scores.

\section{Results}

\section{Incremental Validity Check}

Table 2 displays the results of the hierarchical multiple regression analyses and partial $F$-tests. These results suggest that indicators of positive and negative spirituality explain unique variance in each outcome above and beyond what is already explained by knowledge of the levels of a person's FFM personality traits.

\begin{tabular}{|c|c|c|c|c|c|c|}
\hline & \multirow{2}{*}{\multicolumn{2}{|c|}{$\frac{\text { Negative Affect }}{\beta}$}} & \multicolumn{2}{|c|}{ Positive Affect } & \multicolumn{2}{|c|}{ Satisfaction with Life } \\
\hline & & & \multicolumn{2}{|c|}{$\beta$} & \multicolumn{2}{|c|}{$\beta$} \\
\hline & \\
\hline FFM $R^{2}$ & $.35^{* * *}$ & & $.50^{* * *}$ & & $.29 * * *$ & \\
\hline \multicolumn{7}{|c|}{ Model 2} \\
\hline FFM $R^{2}$ & $.43^{* * *}$ & & $.60^{* * *}$ & & $.35^{* * *}$ & \\
\hline Spirituality $\Delta R^{2}$ & $.08^{* * *}$ & & $.10^{* * *}$ & & $.06^{* *}$ & \\
\hline Neuroticism & & $.43^{* * *}$ & & $-.50^{* * *}$ & & $-.39 * * *$ \\
\hline Extraversion & & -0.07 & & 0.06 & & 0.12 \\
\hline Openness & & 0.05 & & 0.01 & & -0.09 \\
\hline Agreeableness & & 0.01 & & -0.08 & & 0.08 \\
\hline Conscientiousness & & 0.02 & & $.13^{*}$ & & 0.08 \\
\hline Religious Involvement & & $.17^{*}$ & & -0.04 & & -0.11 \\
\hline Spiritual Transcendence & & -0.05 & & 0.07 & & 0.13 \\
\hline Faith Maturity & & -0.12 & & 0.1 & & 0.06 \\
\hline Punished by God & & -0.1 & & 0.1 & & 0.09 \\
\hline Abandoned by God & & $.17^{*}$ & & -0.05 & & $-.19^{*}$ \\
\hline Isolated from Faith Community & & $.20^{*}$ & & $-.33^{* * *}$ & & -0.08 \\
\hline
\end{tabular}

Note: ${ }^{*} \mathrm{p}<.05,{ }^{* *} \mathrm{p}<.01,{ }^{* * *} \mathrm{p}<.001$. List wise $\mathrm{N}$ for all models $=158$.

Table 2: Incremental Validity of the Spirituality Indicators over FFM Personality Domains.

\section{Structural Equation Modelling}

Results indicated that Model 1 (Figure 1) fit the data exactly $\left[\chi^{2} s-B(24)=33.46, p=.095\right]$ while Model 2 did not $\left[\chi^{2} s-B(24)=36.42, p=0.050\right]$. These results supported the hypothesis that spirituality would emerge as the underlying cause of psychological flourishing, rather than the reverse, and suggest that Model 1 is a viable 


\section{Mental Health \& Human Resilience International Journal}

explanation of the potential causal relations among the constructs. Also in Model 1 (Figure 1), the standardized loadings of all indicators on their constructs were large and statistically significant $(p<.05)$, indicating that these were plausible reflections of the underlying construct. Finally, all of the standardized structural path coefficients in Model 1 were statistically significant $(p<.05)$ except for the path from positive spirituality (poSpirit) to psychological flourishing (Flourish). These results supported the hypothesis that negative spirituality $(\beta=-$ $.63, p<.05)$ would have greater influence on psychological flourishing than positive spirituality.

\section{Discussion}

The exact fit of Model 1 (Figure 1), in which spirituality causes psychological flourishing and negative spirituality uniquely predicted flourishing whereas positive spirituality did not, carries at least two implications. First, a religiously committed individual's happiness and satisfaction with life appears to arise out of his or her spirituality. Second, when simultaneously assessing the effects of negative and positive experiences of the individual's relationship with God and his or her faith group, the committed individual's sense of happiness and satisfaction with life appear to be more immediately influenced by the negative spiritual experiences rather than the positive ones.

One possible explanation for the plausibility of Model 1 (Figure 1) is that negatively valenced spiritual experiences have psychological consequences within the same parameters of negative appraisals and negatively valenced events in the human psyche, having an immediate, intense impact on subjective well-being. This potential explanation is consistent with Baumeister, Bratslavsky, Finkenauer, and Vohs' [8] analysis of the psychological literature on the effects of negative and positive events. Baumeister, et al. [8] found negatively valenced events to have a broader, more intense and immediate impact on both negative and positive developmental, health, interpersonal, learning, and psychological outcomes, whereas positively valenced events appeared to impact only positive outcomes.

The similarity of the model-implied function of negative spirituality to the function of negatively valenced events in the human psychological system is also consistent with d'Aquili and Newberg's [1] idea that the human capacity for religious and spiritual experience engages the excitatory and inhibitory systems of the brain. As shown in Model 1, these experiences have potential consequences in their associated positive and negative cognitive-affective systems. If these explanations were true, then these warrant more careful empirical investigation into the mechanisms by which religious and spiritual sources of psychological distress are created, the types of distress and associated behaviours that they cause, and the psycho-spiritual mechanisms by which the distress may be ameliorated.

While the exact fit of Model 1 is encouraging, the modelling study presented in this paper is limited by several design concerns: a cross sectional sample of convenience of self-reported observations; a range of participants restricted to mostly conservative Christian denominations; and, a lack of causal design elements such as randomization, experimental manipulation of the salience of the predictors, and a longitudinal structure for assessing temporal precedence or potential non-recursive relationships. The use of a probability sample would allow for implications to be applied to the larger population. The use of experimental manipulation of the salience of predictors would allow direct discussion of causal mechanisms as opposed to hypothesized modelimplied causes. A longitudinal structure would satisfy the requirement of temporal sequence between cause and effect, and allow for the examination of longer term effects of varying frequencies and intensities of positive versus negative spiritual experiences, and the potential buffering effect of positive experiences over a range of time and intensity. It would also allow for the examination of bi-directional causation. Thus, future studies of the mechanisms by which religious and spiritual experiences contribute to psychological distress or flourishing must make use of a (preferably large) probability sample, experimental manipulation of the salience of predictors, and a longitudinal design that models the pathways and intersections of personality, spirituality, and psychological flourishing over a lifetime.

\section{References}

1. d'Aquili EG, Newberg AB (2000) The neuropsychology of aesthetic, spiritual and mystical states. Zygon 35(1): 39-52.

2. Newberg AB, d'Aquili EG (2000) The neuropsychology of religious and spiritual experience. Journal of Consciousness Studies 7: 251266.

3. Koenig HG, Kind DE, Carson VB (2012) Handbook of religion and health, $2^{\text {nd }}$ (Edn.), Oxford University Press, New York. 


\section{Mental Health \& Human Resilience International Journal}

4. Paloutzian RF, Park CL (2005) The handbook of the psychology of religion. Guilford, New York.

5. Hackney CH, Sanders GS (2003) Religiosity and mental health: A meta-analysis of recent studies. Journal for the Scientific Study of Religion 42(1): 4355.

6. WHOQOL SPRB Group (2006) A cross-cultural study of spirituality, religion and personal beliefs as components of quality of life. Social Science and Medicine 62(6): 1486-1497.

7. Pargament K (1997) The psychology of religion and coping. Guilford Press, New York.

8. Baumeister RF, Bratslavsky E, Finkenauer C, Vohs KD (2001) Bad is stronger than good. Review of General Psychology 5(4): 323-370.

9. Piedmont RL (2004) Assessment of Spirituality and Religious Sentiments (ASPIRES) technical manual. Columbia.

10. Benson PL, Donahue MJ, Erikson JA (1993) The Faith Maturity Scale: Conceptualization, measurement, and empirical validation. Research in the Social Scientific Study of Religion 5: 1-26.

11. Piedmont RL, Nelson R (2001) A psychometric evaluation of the short form of the Faith Maturity Scale. Research in the Social Scientific Study of Religion 12: 165-183.
12. Watson D, Clark LA, Tellegen A (1988) Development and validation of brief measures of positive and negative affect: the PANAS scales. Journal of Personality and Social Psychology 54(6): 1063-1070.

13. Diener E, Emmons RA, Larsen RJ, Griffin S (1985) The Satisfaction with Life Scale. Journal of Personality Assessment 49(1): 71-75.

14. International Personality Item Pool: A scientific collaboratory for the development of advanced measures of personality traits and other individual differences. Internet Web Site.

15. Goldberg LR, Johnson JA, Eber HW, Hogan R, Ashton MC, et al. (2006) The International Personality Item Pool and the future of public-domain personality measures. Journal of Research in Personality 40: 8496.

16. Sechrest L (1963) Incremental validity: A recommendation. Educational \& Psychological Measurement 23: 153-158.

17. Piedmont RL (2006) The role of personality in understanding religious and spiritual constructs. In: Paloutzian RF, Park CL (Eds.). The handbook of the psychology of religion. Guilford, New York.

18. Jöreskog KG, Sorbom D (2005) LISREL 8.72 [statistical software]. IL: Scientific Software International, Lincolnwood. 